\title{
POPULATION STRUCTURE, GENE FLOW AND NATURAL SELECTION IN POPULATIONS OF EUPHYDRYAS PHAETON
}

\author{
PETER F. BRUSSARD and A. THOMAS VAWTER \\ Section of Ecology and Systematics, Langmuir Laboratory, Cornell University, \\ Ithaca, New York 14853
}

Received 24.ix.74

\section{Summary}

\begin{abstract}
An examination of seven proteins, presumably encoded by seven structural gene loci, in three local populations of the supposedly sedentary and colonial butterfly, Euphydryas phaeton revealed that three (43 per cent) were polymorphic with three to five alleles each. In addition to this high level of heterozygosity, no statistically significant differences in allele frequencies were found at two of the three polymorphic loci. Since the effective breeding size in each population was estimated to range from as few as 20 to 200 individuals, it appears that some level of gene flow between populations must be invoked to explain the high levels of genetic variability maintained in local populations of this butterfly, despite its apparently colonial nature.
\end{abstract}

\section{Introduction}

ONE of the important problems in ecological genetics is to account for the levels of genetic variation observed in natural populations in terms of relevant environmental parameters. The spatial arrangement of populations, their size, their persistence through time, and the amount of gene flow between them all have important effects on genetic variation and are clearly attuned to the ecology of the species involved.

Differences in electrophoretic mobilities of proteins can readily be ascribed to a genetic model and are commonly used to estimate degrees of genetic similarity between populations. Unfortunately, few data of this type exist which are accompanied by ecological information. In this paper we describe essential genetic similarity of three local populations of the butterfly Euphydryas phaeton, and discuss the type of population structure from which the similarity evidently results.

Butterflies in the genus Euphydryas have been the subject of numerous studies in population biology, beginning with the classic work of Ford and Ford (1930) concerning changes in numerical abundance and phenotypic variability in the Marsh Fritillary butterfly, E. aurinia. More recently, Ehrlich and his co-workers at Stanford University have conducted an intensive, long-term study of the population biology of $E$. editha at the Jasper Ridge colony (for a recent summary of this work see Brussard, Ehrlich and Singer, 1974) and elsewhere (Singer, 1971; Gilbert and Singer, 1973; White, 1974; White and Singer, 1974). Brown and Ehrlich (1974) have recently completed a 3-year analysis of populations of $E$. chalcedona at Jasper Ridge. In addition to these studies we have now begun a detailed investigation into the population biology of Euphydryas phaeton with the aid of electrophoretic data. 


\section{Methods AND Results}

Euphydryas phaeton is relatively common in upstate New York, but it is confined to wet, low areas where its foodplant, turtlehead (Chelone glabra, Scrophulariaceae), grows; and locating accessible colonies in which the insects are sufficiently abundant for study can be difficult. Two such colonies were located; one in fields near Cornell University's Langmuir Laboratory, a second in Shindagin Hollow, south-east of Ithaca. The two colonies are approximately $18 \mathrm{~km}$ apart, in different drainages, and are separated by a considerable expanse of unsuitable habitat, although a number of small, intervening populations exist.

In the Langmuir colony the insects are concentrated in, but not completely confined to, several small, low, wet areas. During the course of the 1973 flight season (5th-26th July) a mark-release-recapture programme, similar to the one described by Brussard, Ehrlich and Singer (1974), was conducted in this population. Total population size for the year was estimated as follows: minimum 86 (= number marked), estimate $213 \pm 109$. It was also found that 88 per cent of the recaptured butterflies were recaptured within $50 \mathrm{~m}$ of the locality where they were marked, and none was ever recaptured more than $100 \mathrm{~m}$ from that locality. Fifty-three individuals from this population were collected for electrophoresis during the flight season.

In the Shindagin Hollow colony the insects were concentrated in two areas, one in a very wet meadow at the headwaters of a small creek, the other at a farm pond on a hillside about $200 \mathrm{~m}$ from the creek and draining into it. During the flight season 56 individuals were collected for electrophoresis from the meadow locality, and 18 were collected from the area adjacent to the pond. No butterflies were observed in the area between the pond and the meadow. A relative estimate of the size of these populations, based upon catch per unit effort (man-hours of netting), was made and calibrated to the absolute estimate from Langmuir Fields. We estimate that approximately 50 butterflies inhabited the pond area, and that there were fewer than 200 in the meadow.

After collection, butterflies were returned to the laboratory and frozen at $-80^{\circ} \mathrm{C}$ until electrophoresis. Specimens were prepared by removing the wings and legs and crushing the whole body in a $10 \times 75 \mathrm{~mm}$ polypropylene centrifuge tube containing $0.4 \mathrm{ml}$ of cold buffer $(0.1 \mathrm{M}$ Tris, $0.00 \mathrm{~lm}$ EDTA, $5 \times 10^{-5} \mathrm{M}$ NADP, with $\mathrm{pH}$ adjusted to $7 \cdot 0$ with $\left.\mathrm{HCl}\right)$. The samples were then sonicated using a Bransonik IV (Bronwill) for 30 seconds while kept at $0^{\circ} \mathrm{C}$ in an ice bath. Then they were centrifuged at 15,000 rpm in a chilled high-speed centrifuge (International Equipment Co.) for 20 minutes. The clear supernatant was removed and stored at $-80^{\circ} \mathrm{C}$ until electrophoresis.

We used horizontal starch gel electrophoresis and staining procedures similar to those described by Selander et al. (1971), and were able to resolve clearly seven anodally migrating proteins presumably encoded by seven structural gene loci. The buffer systems used and the enzymes assayed are as follows: lithium hydroxide (Selander et al., 1971, buffer 2), glutamateoxaloacetate transaminase (GOT, 1 locus), phosphohexose isomerase (PHI, 1 locus), phosphoglucomutase (PGM, 2 loci), and tetrazolium oxidase (TO, 1 locus); phosphate (Selander et al., 1971, buffer 7), $\alpha$ glycerophosphate dehydrogenase ( $\alpha$-GPD, 1 locus), and malate dehydrogenase (MDH, 1 locus). Three of the seven loci (PHI, MDH, and PGM-2) 
were polymorphic. $\mathrm{MDH}$ and $\mathrm{PHI}$ are structural dimers, the heterozygotes showing three bands; PGM-2 is monomeric with two-banded heterozygotes. Patterns were exceedingly clear and the possibility of scoring errors at any locus is remote Loci were numbered and alleles designated in order of decreasing anodal mobility.

Allele frequencies, determined by direct count from the phenotypes observed on the gels, were used to calculate the expected genotypic frequencies by Levene's (1949) method for small samples. Deviations of observed from expected values were tested for significance using the G-test for goodness-of-fit (Sokal and Rohlf, 1969). Where appropriate, rare alleles were pooled for statistical analysis. No statistically significant departures from Hardy-Weinberg equilibrium were observed.

TABLE 1

Sample sizes, allele frequencies, number of effective alleles per locus $\left(\mathrm{n}_{\mathbf{e}}\right)$, and frequency of heterozygous individuals for three polymorphic loci from three local populations of $\mathrm{E}$. phaeton

\begin{tabular}{|c|c|c|c|c|c|c|c|c|}
\hline & $\begin{array}{l}\text { Sample } \\
\text { size }\end{array}$ & $a$ & $b$ & $c$ & $d$ & $e$ & $n_{e}$ & $\begin{array}{c}\text { Frequency of } \\
\text { heterozygous } \\
\text { individuals }\end{array}$ \\
\hline \multicolumn{9}{|l|}{ PHI } \\
\hline Langmuir & 53 & $0 \cdot 113$ & 0.830 & 0.019 & 0.038 & - & $1 \cdot 42$ & 0.36 \\
\hline Upper Shindagin & 18 & 0.111 & $0 \cdot 833$ & - & - & $0 \cdot 056$ & $1 \cdot 41$ & 0.33 \\
\hline Lower Shindagin & 49 & 0.133 & 0.796 & $0 \cdot 010$ & $0 \cdot 020$ & $0 \cdot 010$ & $1 \cdot 53$ & $0 \cdot 37$ \\
\hline
\end{tabular}

Interpopulation heterogeneity: $\mathrm{G}=0.488$, d.f. $=2,0.9>\mathrm{P}>0.5$

$\mathrm{MDH}$

\begin{tabular}{|c|c|c|c|c|c|c|}
\hline Langmuir & 46 & $0 \cdot 880$ & $0 \cdot 109$ & 0.011 & $1 \cdot 27$ & $0 \cdot 24$ \\
\hline Upper Shindagin & 18 & 0.889 & 0.083 & 0.027 & $1 \cdot 25$ & $0 \cdot 22$ \\
\hline Lower Shindagin & 46 & 0.750 & $0 \cdot 207$ & 0.043 & $1 \cdot 65$ & $0 \cdot 39$ \\
\hline
\end{tabular}

Interpopulation heterogeneity: $\mathrm{G}=6.541$, d.f. $=2,0.5>\mathrm{P}>0.025$

\section{PGM-2}

Langmuir

Upper Shindagin

Lower Shindagin

49
18
49

$\begin{array}{llll}- & 0.286 & 0.643 & 0.071 \\ - & 0.306 & 0.528 & 0.167 \\ 0.031 & 0.388 & 0.520 & 0.061\end{array}$

Interpopulation heterogeneity: $\mathrm{G}=7 \cdot 205$, d.f. $=4,0.5>\mathrm{P}>0 \cdot 1$

The number of alleles at each locus, rare ones pooled when appropriate, were compared among populations using a G-test for homogeneity (Sokal and Rohlf, 1969). There was no significant heterogeneity among the populations at the PGM-2 or PHI loci. At the MDH locus there was significant heterogeneity $(G=6.541$, d.f. $=2,0.05>P>0.025)$ among the three populations. We used the STP procedure (Sokal and Rohlf, 1969) to determine if all populations were heterogeneous for $\mathrm{MDH}$ or if there was any set of homogeneous populations. Upper Shindagin and Langmuir were homogeneous $(G=0.018$, d.f. $=1,0.9>P>0.5)$, but there was a suggestive, although non-significant difference $(G=3.340$, d.f. $=1,0.1>P>0.05)$ between Upper and Lower Shindagin. Significant heterogeneity existed between Lower Shindagin and Langmuir $(G=5 \cdot 289$, d.f. $=1,0.025>P>$ $0.01)$.

Gene frequencies, sample sizes, number of effective alleles per locus $\left(n_{e}\right.$ : Kimura and Crow, 1964), frequency of heterozygous individuals, and the statistics for interpopulation heterogeneity for the polymorphic loci are given in table 1. Sample sizes for the monomorphic loci are comparable to 
those for the polymorphic ones. Genetic distances between the populations (Nei, 1972) are as follows: Upper Shindagin-Lower Shindagin 0.005, Upper Shindagin-Langmuir 0.002, Lower Shindagin-Langmuir 0.004.

\section{Discussion}

The continuum of population structures is usually considered to have two endpoints. One is Wright's (1951) " neighbourhood " model which describes an extensive population, continuously distributed over a wide area, but in which mating individuals may be restricted to a neighbourhood of limited distance. Such a population structure has been described for the butterfly Erebia epipsodea, which has large, effectively panmictic populations covering thousands of hectares at densities ranging from 5 to 80 individuals per hectare (Brussard and Ehrlich, 1970; Ehrlich et al., 1972).

The other endpoint is the "island" model, in which numerous small, isolated populations seldom, if ever, exchange individuals. Such a population structure has been inferred for E. aurinia (Ford and Ford, 1930) and described for the Jasper Ridge colony of $E$. editha (Ehrlich, 1965). Our first impression was that the structure of $E$. phaeton populations would be similar to this model, since the colonies are restricted in extent, and individuals are not often observed to stray far from the low-lying wet areas which constitute favourable habitat. Clearly movement between neighbouring populations should be inhibited by such apparently sedentary behaviour. Yet in spite of this, our data show only one statistically significant difference at one locus between two of the three seemingly isolated local populations. Furthermore, each population maintains a high degree of genetic variability.

Lack of local and regional genetic differentiation has been previously reported for numerous species of Drosophila (O'Brien and MacIntyre, 1969; Prakash, Lewontin and Hubby, 1969; Ayala, Powell and Dobzhansky, 1971; Ayala et al., 1972; Rockwood-Sluss, Johnston and Heed, 1973). The same phenomenon is now documented for other species of lepidoptera: Hemiargus isola (Burns and Johnson, 1971), Phyciodes tharos (Vawter and Brussard, 1974), and Pieris rapae (Vawter and Brussard, in preparation). All these species show a remarkable similarity in allele frequencies and high levels of heterozygosity, both in widely separated populations and on a local level. Euphydryas phaeton, however, is the first supposedly highly colonial, sedentary insect for which similar data have been obtained.

Ignoring the interpopulation heterogeneity at the $\mathrm{MDH}$ locus for the moment, let us consider how genetic continuity at PHI and PGM-2 can be maintained under conditions of the island model of population structure, assuming that there is no migration between local groups. For neutral alleles, the number of effective alleles that can be maintained per locus is

$$
n_{e}=4 \mathcal{N}_{e} m+1
$$

where $\mathcal{N}_{\boldsymbol{e}}$ is the effective population size and $m$ is the mutation rate (Kimura and Ohta, 1971). If the polymorphisms we have studied in E. phaeton are selectively neutral, and assuming a mutation rate of $10^{-7}$ mutations per locus per generation (Ayala, 1972), the effective population size for each $E$. phaeton population would have to be nearly four million individuals to maintain this level of genetic variability. This number is clearly at variance with our data. Even if we have seriously underestimated the population sizes, it is highly unlikely that we have done so by more than four orders of magnitude! 
There is strong circumstantial evidence, moreover, that the average effective population size of an E. phaeton colony is even smaller than our 1973 estimates indicate. The Lower Shindagin Hollow population occupies wet bottomland which may have provided a suitable habitat for hundreds of years. It is far from stable, however; during Hurricane Agnes of 1972 this area was under several feet of water at a time when $E$. phaeton caterpillars would have been in their penultimate or last instars, a circumstance which must have caused heavy mortality and reduced the population to an extremely low level if not eliminated it altogether that year. Such hurricanes are known to occur in upstate New York about once every 20 years. Thus, periodic replacement of some populations must certainly occur at irregular intervals.

The Upper Shindagin Hollow population and the one in Langmuir Fields occupy areas which were forest less than 100 years ago; in fact, the Langmuir Fields were under cultivation about 20 years ago. Thus, these populations occupy habitats which have only recently become suitable, and as such, must have undergone some sort of a colonisation " bottleneck".

In addition to the colonisation bottlenecks at Upper Shindagin and Langmuir and the strong probability of recent extinction or near extinction of the Lower Shindagin population due to flooding, evidence from other Euphydryas species suggests that $E$. phaeton populations in general may undergo periodic reductions in numbers that are not directly related to habitat stability. According to Ford and Ford (1930) populations of E. aurinia " have a well-known tendency to die out, or, rather, to dwindle to a few odd individuals for a number of years, and then to reappear again rather suddenly ....". A similar phenomenon has been observed repeatedly in populations of E. editha (Ehrlich, 1965; Brussard, Ehrlich and Singer, 1974). There is no reason to believe that similar demographic troughs do not occur in $E$. phaeton.

Since the effective population size in populations which undergo periodic fluctuations in numbers is the harmonic mean of the numbers of any one cycle, the effective size is controlled largely by the phase of small numbers (Kimura and Ohta, 1971). For these reasons, the average effective population size of an E. phaeton colony is probably closer to 20 than 200 . Therefore, it is hard to see how the number of alleles observed at each locus could be maintained in populations this small in the absence of gene flow, regardless of whether the polymorphisms are neutral or not.

How much gene flow, then, is enough to account for these data? For neutral alleles, the amount of migration which must take place between neighbouring local populations to maintain alleles in similar frequencies is such that

\section{$\mathcal{N} m>4$}

where $\mathcal{N}$ is the effective size of the local population and $m$ is the rate of migration between local populations per generation (Kimura and Ohta, 1971). If one assumes an effective population size of 20 in these populations, the interpopulation movement of one individual every five generations would be sufficient to account for the observed similarities. Clearly, migration rates of such magnitude are extremely difficult to measure. If periodic replacement of these populations occurs, however, much larger migration rates must be invoked to explain the levels of variability observed. 
Suppose, on the other hand, that these polymorphisms are not selectively neutral, a view shared by most evolutionists who have studied actual populations (Ayala, 1972; Stebbins and Lewontin, 1972). If selection pressures in the various populations were similar, allele frequencies would also be expected to be very similar, and gene flow would have little effect (Wallace, 1968, p. 81; Ehrlich and Raven, 1969). If the environments differed in ways which could have a direct effect on allele frequencies at these loci, local differentiation could still occur, even in the face of considerable gene flow (Creed et al., 1962; Aston and Bradshaw, 1966; Jain and Bradshaw, 1966; Endler, 1973).

An important question, however, is whether or not movement of individuals between two $E$. phaeton populations would actually result in gene flow. A dispersing male would probably arrive in a distant population too late to inseminate a virgin female. Therefore, sedentary behaviour in established populations would almost certainly be selected for in males. However, at least in upstate New York, a dispersing female arriving in a new population even toward the end of the year's flight season would still find many suitable oviposition sites. Thus, sedentary behaviour would not necessarily be selected for in females, at least after mating. In fact, the occasional inseminated female that happened upon a suitable but unoccupied patch of habitat would probably enjoy a bonanza of increased fitness. This is an important contrast between the ecology of $E$. phaeton and that of $E$. editha, whose habitat becomes unsuitable for oviposition toward the end of the flight season due to senescence of the food plants (Gilbert and Singer, 1973).

Burns and Johnson (1971) presented evidence that gene flow in the lycaenid butterfly Hemiargus isola was accomplished by interpopulation movement of previously mated females, and they concluded that this migration was responsible for maintaining interpopulation homogeneity of allele frequencies at the loci they examined. That the dispersal tendency of gravid females is responsible for gene flow in other species of lepidoptera is also suggested by the work of Shapiro (1970) in Pieris protodice.

There is some evidence that the dispersal tendency of female $E$. phaeton is different from that of males, since recapture rates of the two sexes differ. For example, at Langmuir Fields 23 per cent of the males marked were recaptured once, 14 per cent twice, and 3 percent more than twice $(\mathcal{N}=65)$, while of the females marked $(\mathcal{N}=21), 25$ per cent were recaptured once and none was recaptured more than once. Similar differences in recapture percentages have been described in E. editha, but these are attributed primarily to different "catchability" of males and females resulting from incessant trivial movements in males (Ehrlich, 1965). Although we have observed similar behavioural differences in E. phaeton, it is likely that our recapture results reflect unlike dispersal tendencies between the sexes, since female dispersal is also documented by other collection records. Shapiro (personal communication) had captured female $E$. phaeton as far as $12 \mathrm{~km}$ from the nearest known colony, and in stands of vegetation completely unlike normal habitat.

Therefore, some level of dispersal, most likely by mated females, supplies the variation manifest in small local populations of $E$. phaeton. It may take considerable selective pressure, however, to maintain this variation under the conditions of frequent bottlenecking which we hypothesise. This pressure 
could either result in maintaining some allele frequencies at similar levels, or in producing some measure of local differentiation in accordance with local habitat types.

The environments at Shindagin Hollow and Langmuir differ somewhat in detail. The Shindagin Hollow locality is approximately $100 \mathrm{~m}$ higher in elevation than Langmuir. This difference is reflected by the slightly dissimilar climax vegetation in the two areas and in the phenology of the two colonies: in Shindagin Hollow the butterflies emerge about a week later than the ones in Langmuir. However, there are other habitat parameters which must be considered as well. Both Langmuir and Upper Shindagin are in old-field sites rather than permanent bottomland, and these microsite differences could well be more important selective forces than those associated with obvious differences in elevation. The importance of microsite differences to the survival of $E$. editha larvae has been well documented by Singer (1972). In this case, however, the effects of elevation or microsite on either the heterogeneity at the $\mathrm{MDH}$ locus or the homogeneity at the other loci will remain wholly in the realm of speculation until we are able to measure these environments in ways which are relevant to butterfly survival and differential reproduction.

\section{Conclusions}

This type of population structure, intermediate between the strict coloniality of Euphydryas editha and the "ubiquitousness" of Erebia epipsodea (Brussard and Ehrlich, 1971), is obviously advantageous to an insect with rather exacting habitat requirements, but whose habitat is somewhat unstable. Periodic catastrophes or the process of ecological succession evidently forces it into a modified fugitive strategy. Females dispersing from their populations of origin are available to increase genetic variability in small or dwindling populations and colonise newly suitable or previously depopulated areas. The relative efficacies of selection and gene flow in maintaining the observed patterns cannot be determined from the data at hand, however.

Populations of $E$. phaeton provide an interesting contrast to those of $E$. editha which inhabit the serpentine grasslands in California. Since the large serpentine areas in that state are rich in endemic plant species and maintain unique vegetation types (Johnson, Keith, and Ehrlich, 1968), they have probably provided continuously suitable habitat for that species for thousands of years. This has allowed selection for extremely sedentary behaviour and fine-scale tracking of local environments, a strategy not available to $E$. phaeton.

Acknowledgments. - This research was supported by National Institutes of Health grant GM18329 and National Science Foundation grant GB26224. D. F. Nielsen assisted with the field work and the electrophoresis. W. L. Brown, Jr, P. R. Ehrlich, A. M. Shapiro, B. Wallace, R. R. White, and R. H. Whittaker read the manuscript and made several helpful suggestions.

\section{RefERENGeS}

ASTON, R. L., AND BRADSHAw, A. D. 1966. Evolution in closely adjacent plant populations. II. Agrostis stolonifera in maritime habitats. Heredity, 21, 649-664.

AyAlA, F. J. 1972. Darwinian versus non-Darwinian evolution in natural populations of Drosophila. Proc. Sixth Berkeley Symp. Mathematical Statistics and Probability, 5, 211-236. 
Ayala, F. J., POWell, J. R., AND DObzhansky, T. 1971. Polymorphisms in continental and island populations of Drosophila willistoni. Proc. Nat. Acad. Sci. U.S.A., 68, 2480-2483.

AYAla, F. J., POWEll, J. R., TRACEy, M. L., MOURAO, C. A., AND PEREZ-Salas, s. 1972. Enzyme variability in the Drosophila willistoni group. IV. Genic variation in natural populations of Drosophila willistoni. Genetics, 70, 113-139.

BROWN, I. L., AND EHRLICH, P. R. 1974. Population biology of the butterfly, Euphydryas chalcedona-structure of the Jasper Ridge colony. (Submitted to Evolution).

BRUSSARD, P. F., AND EHRLICH, P. R. 1970. The population structure of Erebia epipsodea (Lepidoptera: Satyrinae). Ecology, 51, 119-129.

BRUSSARD, P. F., AND EHRLICH, P. R. 1971. Contrasting population biology of two species of butterfly. Nature, 227, 91-92.

BRUSSARD, P. F., EHRLICH, P. R., AND SINGER, M. C. 1974. Adult movements and population structure in Euphydryas editha. Evolution, 28, 408-415.

BURNS, J. M., AND JOHNSON, F. M. 1971. Esterase polymorphism in the butterfly Hemiargus isola: stability in a variable environment. Proc. Nat. Acad. Sci. U.S.A., 68, 34-37.

CREED, E. R., DOWDESWELl, W. H., FORD, E. B., AND MCWHIRTER, K. G. 1962. Evolutionary studies on Maniola jurtina: the English mainland, 1959-1960. Heredity, 17, 237-265.

EHRLICH, P. R. 1965. The population biology of the butterfly, Euphydryas editha. II. The structure of the Jasper Ridge colony. Evolution, 19, 327-336.

EHRLICH, P. R., BREEDLOVE, D. E., BRUSSARD, P. F., AND SHARP, M. A. 1972. Weather and the "regulation" of subalpine populations. Ecology, 53, 243-247.

EHRLICH, P. R., AND RAVEN, P. H. 1969. Differentiation of populations. Science, 165, 1228. 1232.

ENDLER, J. A. 1973. Gene flow and population differentiation. Science, 179, 243-250

FORD, H. D., AND FORD, E. B. 1930. Fluctuation in numbers and its influence on variation in Melitaea aurinia. Trans. R. ent. Soc. Lond., 78, 345-351.

GILBERT, L. E., AND SINGER, M. C. 1973. Dispersal and gene flow in a butterfly species. Amer. Natur., 107, 58-72.

JAIN, s. K., AND BRADShAw, A. D. 1966. Evolutionary divergence among adjacent plant populations. Heredity, 21, 407-441.

JOHNSON, M. P., KEITH, A. D., AND EHRLICH, P. R. 1968. The population biology of the butterfly Euphydryas editha. VII. Has E. editha evolved a serpentine race? Evolution, 22, 422-423.

KIMURA, M., AND CROW, J. F. 1964. The number of alleles that can be maintained in a finite population. Genetics, 49, 725-738.

kimura, м., AND Ohta, T. 1971. Theoretical Aspects of Population Genetics, 219 pp. Princeton University Press, Princeton, N.J.

LeVEne, H. 1949. On a matching problem arising in genetics. Ann. Math. Stat., 20, 91-94. NEI, M. 1972. Genetic distance between populations. Amer. Natur., 106, 283-292.

O'BRIEN, s. J., AND MACINTYRE, R. J. 1969. An analysis of gene-enzyme variability in natural populations of Drosophila melanogaster and D. simulans. Amer. Natur., 103, 97-113.

PRAKASI, s., LEWONTIN, R. C., AND HUBBY, J. L. 1969. A molecular approach to the study of genic heterozygosity in natural populations. IV. Patterns of genic variation in central, marginal and isolated populations of Drosophila pseudoobscura. Genetics, 61, 841-858.

ROCKWOOD-SLuss, E. s., JOHNSTON, J. S., AND HEED, w. B. 1973. Allozyme genotypeenvironment relationships. I. Variations in natural populations of Drosophila pachea. Genetics, 73, 135-146.

SELANDER, R. K., SMITH, M. H., YANG, S. Y., JOHNSON, W. E., AND GENTRY, J. B. 1971. Biochemical polymorphism and systematics in the genus Peromyscus. I. Variation in the old-field mouse (Peromyscus polionotus). Stud. Genet., VI, 49-90 (Univ. Texas Publ. 7103).

SHAPIRO, A. M. 1970. The role of sexual behaviour in density-related dispersal of Pierid butterflies. Amer. Natur., 104, 367-372.

SINGER, M. C. 1971. Evolution of food-plant preferences in the butterfly Euphydryas editha. Evolution, 25, 383-389.

SINGER, M. C. 1972. Complex components of habitat suitability within a butterfly colony. Science, 176, 75-77.

SOKAl, R. R., AND ROHLF, F. J. 1969. Biometry: The Principles and Practice of Statistics in Biological Research, 776 pp. Freeman, San Francisco.

STEBBINS, G. L., AND LEWONTIN, R. C. 1972. Comparative evolution at the levels of molecules, organisms, and populations. Proc. Sixth Berkeley Symp. Mathematical Statistics and Probability, 5, 43-68. 
VAwTer, A. T., AND BRUSSARD, P. F. 1974. Genetic stability of populations of Phyciodes tharos (Nymphalidae: Melitaeinae). 7. Lepid. Soc. (in press).

wallace, B. 1968 . Topics in Population Genetics, 481 pp. Norton, N.Y.

WHITE, R. R. 1974. Food plant defoliation and larval starvation of Euphydryas editha. Oecologia, 14, 307-315.

WhITE, R. R., AND SINGER, M. C. 1974. Geographical distribution of hostplant choice in Euphydryas editha (Nymphalidae). 7. Lepid. Soc., 28, 103-107.

WRIGHT, s. 1951. The genetical structure of populations. Ann. Eugenics, 15, 323-354. 